\title{
A case-control study of risk factors for HIV- negative children with cryptococcal meningitis in Shi Jiazhuang, China
}

\author{
Jianhua Guo ${ }^{1,4^{*}}$, Jikun Zhou ${ }^{1 \dagger}$, Shiyong Zhang ${ }^{1}$, Xin Zhang ${ }^{2}$, Jing $\mathrm{Li}^{3}$, Yinqi Sun ${ }^{3}$ and Shunxiang $\mathrm{Qi}^{3}$
}

\begin{abstract}
Background: Although cryptococcal meningitis (CM) is an emerging disease worldwide, there have been few studies of the characteristics and risk factors of $\mathrm{CM}$ in children.

Methods: We used data collected from May 2007 through April 2012 in the Acute Meningitis-Encephalitis Syndrome Surveillance project in Shi Jiazhuang, China to describe the epidemiologic, clinical, and laboratory findings in children with CM. Furthermore, a matched case-control study was used to determine risk factors of CM.

Results: Overall 23 HIV-negative children with CM (median age: 10.91 years; range: 5 months-17 years) were enrolled in our study. The average annual incidence of CM was $0.43 / 100,000$ with a fatality rate of $1.7 \%$. Most patients were males (60.87\%) and rural children (73.91\%). Common clinical symptoms included increased intracranial pressure, such as headaches (78.3\%), nausea (60.9\%), altered mental status (56.5\%), vomiting (52.2\%), and seizures (43.5\%), and frequent laboratory findings consisted of blood leukocytosis (87.0\%), decreased CSF glucose (87.0\%), pleocytosis (82.6\%), increased intracranial pressure (73.9\%) and elevated CSF proteins (65.2\%). Epidemiologic, clinical, and laboratory findings were similar between patients with and without underlying diseases. Multivariate logistic regression analysis showed that children who had contact with birds/bird droppings or saprophytes were more likely to be infected than those without such contact (odds ratio(OR) $=11.82 ; 95 \%$ confidence interval $(C \mathrm{Cl}), 2.21-62.24 ; P=0.004)$. Patients with an interval of $\geq 20$ days from onset to admission were at high risk for $C M(O R=5.31 ; 95 \% C l, 1.58-17.89 ; P=0.007)$.

Conclusions: Our findings show that CM is an uncommon disease with a high mortality rate in children. Although additional studies are needed to find effective prevention and treatments for CM, clinicians should consider CM as a potential cause for pediatric meningitis in children, particularly boys from rural areas, who had contact with birds/bird droppings or saprophytes and in children who did not receive prompt medical attention.
\end{abstract}

Keywords: Cryptococcosis, Cryptococcal meningitis, Epidemiologic characteristics, Clinical features, Bird droppings and sacrophytes, Risk factors, Children

\section{Background}

Cryptococcosis is an emerging disease arising due to the global HIV/AIDS pandemic. Cryptococcus neoformans is the most common cause of cryptococcosis worldwide. Cryptococcosis is responsible for cryptococcal meningitis

\footnotetext{
*Correspondence: guoflowers@163.com

${ }^{\dagger}$ Equal contributors

${ }^{1}$ Shi Jiazhuang Center for Disease Prevention and Control (CDC), Shi Jiazhuang 050011, People's Republic of China

${ }^{4}$ Institute for Epidemiology and Health Emergency, Shi Jiazhuang Center for Disease Prevention and Control (CDC), No.3 Li Kang Street, Shi Jiazhuang 050011, China

Full list of author information is available at the end of the article
}

$(\mathrm{CM})$, the most common fungal infection of the central nervous system and a significant cause of morbidity and mortality among patients with HIV/AIDS [1]. Few studies of pediatric CM have been reported, but CM is believed to be less frequent in children than in adults, regardless of immune status [2]. Recently, higher numbers of CM cases in children have been reported worldwide [3-13]. However, these reports come from small case studies, literature reviews, or studies comprised mostly of adults. In addition, the epidemiologic characteristics, clinical features, laboratory findings, and outcomes for pediatric patients are inconsistent among the different studies. Data

\section{Biomed Central}

(c) 2012 Guo et al.; licensee BioMed Central Ltd. This is an Open Access article distributed under the terms of the Creative Commons Attribution License (http://creativecommons.org/licenses/by/2.0), which permits unrestricted use, distribution, and reproduction in any medium, provided the original work is properly cited. 
on the overall incidence of children with $\mathrm{CM}$ are scarce, and understanding which children are at highest risk of $\mathrm{CM}$ is lacking.

Here, we analyzed the epidemiologic characteristics, clinical features, laboratory findings, outcomes, and risk factors for CM in pediatric patients without HIV/AIDS. Study subjects were identified by the Acute Meningitis and Encephalitis Syndrome (AMES) surveillance project in Shi Jiazhuang, China.

\section{Methods}

\section{Data source and study population}

Data for this study were obtained from the Acute Meningitis and Encephalitis Syndrome (AMES) surveillance database. This database contains demographic information, clinical data, laboratory findings, and outcome for AMES patients; trained individuals entered these data into EPIDATA databases (http://www.epidata.dk/history.htm) with the function of Double Entry and Validation.

Surveillance was conducted for the AMES project in 44 referral hospitals with an aggregate population of around 5.2 million from May 2007 through April 2012, in Shi Jiazhuang. The population in Shijiazhuang was stable during the study period. Children $<18$ years old comprise $20.8 \%$ of the total population. Patients with AMES traditionally seek medical care at the referral hospitals rather than at community hospitals and private clinics. Member hospitals receive most of the patients across Shi Jiazhuang. An AMES case was defined as a patient with acute onset of fever $\geq 38^{\circ} \mathrm{C}$, changes in mental status, and/or meningeal signs. Additionally, an initial diagnosis in member hospitals with Japanese encephalitis, viral encephalitis, viral meningitis, viral meningoencephalitis, other encephalitis, meningococcal meningitis, purulent meningitis, cerebrospinal meningitis, tuberculosis meningitis, tuberculosis meningoencephalitis, and other meningitis also qualified as an AMES case. AMES cases were reported to Shi Jiazhuang CDC by clinicians in hospitals. Trained CDC staff performed interviews. To ensure all AMES cases were found, audits were performed every 10 days in each hospital.

Clinicians collected blood ( $\geq 3 \mathrm{~mL}$ ) and/or cerebrospinal fluid (CSF) samples from AMES cases with written informed consent have been obtained from their parents in the case of children younger than 18 years. Routine blood test, CSF test, or culture was conducted at each hospital laboratory. Periodic laboratory audits were performed to ensure case ascertainment in each laboratory. Confirmed AMES case was defined as any AMES patient with a positive pathogen identified by culture from CSF and/or blood. A CM case was defined as an AMES patient with positive cryptococcal culture from CSF and/or blood. Cryptococcal cultures were identified by L-canavanine glycine bromothymol blue agar. C. neoformans fails to cause a color change on the agar, while the color of the agar changes to blue from green in the presence of C. gattii.

\section{Estimates of risk factors}

A matched retrospective case-control study was conducted in a cohort of patients with confirmed AMES to identify risk factors for $\mathrm{CM}$. The case was defined as any patient with CM. The control was defined as any confirmed AMES patient due to another pathogen. All cases and controls were obtained from the AMES database. Each case was matched to four controls, with onset of meningitis occurring within three months of each other. The following data were used to examine the risk factors: gender, age, geographic location, exposure to birds/bird droppings or saprophytes 3 months before illness onset, underlying disease, date of onset of illness, and date of admission.

\section{Data analysis}

Continuous variables were summarized as medians with ranges. Categorical variables were summarized as proportions. Fisher's exact test was used to compare the categorical variable between patients without underlying diseases and those with underlying diseases. Univariate conditional logistic regression models were used to examine gender, age, geographic location, underlying diseases, contact history of birds/bird droppings or saprophytes, and the time interval from illness onset to hospital admission. All variables with a $\mathrm{P}$ value $<0.10$ upon univariate analysis were included in a multivariate conditional logistic regression model to evaluate their independent effects. Backward logistic regression was conducted by removing variables with $\mathrm{P}>0.10$ upon multivariate conditional logistic regression. Statistical significance was defined as $\mathrm{P}<0.05$. Data were analyzed using the Stata version 9.0 statistical software (StataPress, College Station, TX, USA).

\section{Ethical considerations}

The Ethics Committee of Shi Jiazhuang CDC and ethical review committees of each participating hospital approved this study.

\section{Results}

\section{Epidemiologic characteristics}

Over a 5-year study period, 23 cases of pediatric CM (Median age: 10.91 years; Range: 5 months-17 years) due to $C$. neoformans were confirmed from positive CSF cultures of HIV-negative children. The average annual incidence and fatality rate of CM was found to be 0.43 / 100,000 and $1.74 \%$ among children $<18$ years old. Most of the patients identified were males $(60.87 \%)$ and from 
rural environments (73.91\%). About half of the patients (43.48\%) emerged in June-August during the 5-year period. Most cases (78.26\%) had contact with birds/bird droppings or saprophytes before illness onset and $26.1 \%$ of the cases had underlying diseases (1 patients with hepatitis $B, 1$ with renal disease, 1 with diabetes, 1 with aplastic anemia, 1 with tuberculosis, and 1 with hand-footmouth disease). None of the patients had traveled outside his/her district for at least one year before becoming ill. Epidemiologic characteristics of patients with or without underlying diseases did not differ (Table 1).

\section{Clinical features and laboratory findings}

The median duration from illness onset to hospital admission was 33 days (range: $2-48$ days). The initial diagnoses included meningitis $(34.78 \%)$, bacterial meningitis $(30.43 \%)$, viral meningitis $(21.74 \%)$, and tuberculosis meningitis (13.04\%). The first symptoms were actue fever in $78.3 \%$ of the patients and headache in $65.2 \%$. Frequent symptoms and signs were fever (100\%), headache $(78.3 \%)$, nausea $(60.9 \%)$, altered mental status (56.5\%), vomiting (52.2\%), seizures (43.5\%), meningeal signs (34.8\%), and stiff neck (30.4\%) (Table 1). Blood leukocytosis (87.0\%), decreased CSF glucose (87.0\%), pleocytosis (82.6\%), increased intracranial pressure (73.9\%) and elevated CSF proteins (65.2\%) were found in most patients (Table 1). Clinical features and laboratory findings did not differ significantly between patients with or without underlying diseases (Table 1).

\section{Outcome}

The median length of hospitalization was 22 days (range: 13-34 days). One patient without underlying disease and another with renal disease died during hospitalization. At discharge, 18 cases had recovered and 3 cases had complications, one with hearing damage, one with mild papilloedema, and one with blurred vision. These 3 patients had recovered by the 6-month follow-up.

\section{Risk factors}

Univariate conditional logistic analysis was used to identify risk factors associated with CM patients in comparison to patients with other types of meningitis (Table 2). When compared to patients $<5$ years old, patients $\geq 10$ and $<15$ years old (odds ratio $(O R)=4.36 ; 95 \%$ confidence interval (CI), 1.12-9.81; $P=0.033)$ or $\quad$ patients $\geq 15$ and $<18$ years old $(\mathrm{OR}=5.53 ; 95 \% \mathrm{CI}, 1.19-25.79 ; P=$ 0.029 ) were significantly associated with CM. Contact with birds/bird droppings or saprophytes was associated with $\mathrm{CM}(\mathrm{OR}=9.32 ; 95 \% \mathrm{CI}, 2.54-34.23 ; P=0.001)$. An interval of $\geq 10$ days and $<20$ days from illness onset to hospital admission ( $\mathrm{OR}=2.22 ; 95 \% \mathrm{CI}, 0.35-14.15 ; P=0.398)$ was not significantly associated with $\mathrm{CM}$, whereas an interval of $\geq 20$ days from onset to admission was significantly associated with $\mathrm{CM}(\mathrm{OR}=11.39 ; 95 \% \mathrm{CI}, 2.20-59.02 ; P=0.004)$.

Furthermore, we performed a multivariate conditional logistic regression analysis of risk factors for CM (Table 3). Subjects with a history of contact with birds/ bird droppings or saprophytes were more likely to be infected than those without contact $(\mathrm{OR}=11.82$; 95\%CI, 2.21-62.24; $P=0.004$ ).

Overall, our findings suggest that contact with birds/ bird droppings or saprophytes and a longer interval from illness onset to hospital admission are independent risk factors for CM.

\section{Discussion}

Here, we analyzed epidemiology, clinical and laboratory characteristics, and risk factors associated with CM due to $C$. neoformans in HIV-negative children. Similar to the incidence in children of Taiwan with unknown HIV status reported previously [11], we found an average annual incidence of 4.3 cases of CM per million HIVnegative children with a fatality rate of $1.7 \%$ in mainland China.

Two species in the genus Cryptococcus, C. neoformans and C. gattii, can infect humans. The former, which is found commonly worldwide, infects mostly immunocompromised patients $[14,15]$, whereas the latter affects both immunocompetent and immunocompromised individuals $[16,17]$. In our study, children without underlying diseases comprised $74 \%$ of CM patients caused by C. neoformans, consistent with other reports from mainland China [18]. This finding may be explained by the genetic homogeneity between Chinese $C$. neoformans strains [18]. However, data demonstrate that C. gattii, which was formerly described as a geographically restricted species [19], is spreading at a great rate around the globe. Cases caused by this species have been reported not only from the tropical and subtropical areas, but also from the Pacific coast of Canada and the United States [20]. Moreover, China, Europe, and Japan confirm that this fungus can also occur in temperate climates $[18,21,22]$.

The proportion of immunocompetent patients with $\mathrm{CM}$ varies greatly between the HIV-negative patients in different regions and countries [8,23-28], regardless of the age of patients. For example, in Taiwan, about 50\% of HIV-negative children with CM exhibited underlying disease $[8,23]$ whereas $38 \%$ of CM patients in India had no underlying disease [24]; in Vietnam, $81 \%$ of the CM patients had no underlying disease [25], but in the United States, about $70 \%$ of HIV-negative adults with CM had underlying disease [26]. Subtle defects in immunity [27] or idiopathic CD4 lymphopenia [28] could account for these variations, as could ethnic differences. Further studies are needed to determine the cause of 
Table 1 Characteristics of pediatric patients with cryptococcal meningitis

\begin{tabular}{|c|c|c|c|c|}
\hline Characteristic & $\begin{array}{l}\text { Patients without underlying } \\
\text { diseases }(\%)(n=17)\end{array}$ & $\begin{array}{l}\text { Patients with underlying } \\
\text { diseases* }(\%)(n=6)\end{array}$ & $\begin{array}{l}\text { Total [no.(\%)] } \\
(n=23)\end{array}$ & $P$ value \\
\hline \multicolumn{5}{|l|}{ Gender } \\
\hline Male & 11 (78.6) & $3(50.0)$ & 14 (78.6) & 0.643 \\
\hline Age, years & & & & 0.835 \\
\hline $0-5$ & $3(17.6)$ & $1(16.7)$ & $4(17.4)$ & \\
\hline $5-10$ & $5(29.4)$ & $1(16.7)$ & $6(26.1)$ & \\
\hline $10-15$ & $7(41.2)$ & $2(33.3)$ & $9(39.1)$ & \\
\hline $15-17$ & $2(11.8)$ & $2(33.3)$ & $4(17.4)$ & \\
\hline \multicolumn{5}{|l|}{ Geographic location } \\
\hline Rural area & $13(76.5)$ & $4(66.7)$ & $17(73.9)$ & 0.632 \\
\hline Date of illness onset & & & & 0.444 \\
\hline December-February & $5(29.4)$ & $0(0.0)$ & $5(21.7)$ & \\
\hline March-May & $3(17.6)$ & $1(16.7)$ & $4(17.4)$ & \\
\hline June-August & $7(41.2)$ & $3(50.0)$ & $10(43.5)$ & \\
\hline September-November & $2(11.8)$ & $2(33.3)$ & $4(17.4)$ & \\
\hline Contact with birds/droppings or saprophytes $\dagger$ & $12(70.6)$ & $6(100.0)$ & $18(78.3)$ & 0.274 \\
\hline Time from illness onset to hospitalization (days) & & & & 0.093 \\
\hline $1-10$ & $2(11.8)$ & $1(16.7)$ & $3(13.0)$ & \\
\hline $10-20$ & $2(11.8)$ & $1(16.7)$ & $3(13.0)$ & \\
\hline $20-30$ & $11(78.6)$ & $1(16.7)$ & $12(52.2)$ & \\
\hline$\geq 30$ & $2(11.8)$ & $3(66.7)$ & $5(21.7)$ & \\
\hline \multicolumn{5}{|l|}{ Clinical symptoms and signs } \\
\hline Fever $\left(\geq 39^{\circ} \mathrm{C}\right)$ & $8(47.1)$ & $5(83.3)$ & $13(56.5)$ & 0.179 \\
\hline Headache & $13(76.5)$ & $5(83.3)$ & $18(78.3)$ & 1.000 \\
\hline Nausea & $9(52.9)$ & $5(83.3)$ & $14(78.6)$ & 0.340 \\
\hline Altered mental status & $10(58.8)$ & $3(50.0)$ & $13(56.5)$ & 1.000 \\
\hline Vomiting & $10(58.8)$ & $2(33.3)$ & $12(52.2)$ & 0.371 \\
\hline Seizures & $6(35.3)$ & $4(66.7)$ & $10(43.5)$ & 0.341 \\
\hline Meningeal signs & $5(29.4)$ & $3(50.0)$ & $8(34.8)$ & 0.621 \\
\hline Neck stiffness & $6(35.3)$ & $1(16.7)$ & $7(30.4)$ & 0.621 \\
\hline Hearing damage & $3(17.6)$ & $1(16.7)$ & $4(17.4)$ & 1.000 \\
\hline Visual damage & $3(17.6)$ & $0(0.0)$ & $3(13.0)$ & 0.539 \\
\hline Bregmatic eminence & $1(5.9)$ & $0(0.0)$ & $1(4.3)$ & 1.000 \\
\hline \multicolumn{5}{|l|}{ Laboratory findings } \\
\hline Blood leukocytosis ( $\left.\geq 15 \times 10^{9} / \mathrm{L}\right)$ & $15(65.2)$ & $5(83.3)$ & $20(87.0)$ & 1.000 \\
\hline Decreased CSF glucose $(<3.1 \mathrm{mmol} / \mathrm{L})$ & $16(94.1)$ & $4(66.7)$ & $20(87.0)$ & 0.155 \\
\hline Pleocytosis $\left(\times 10^{6} / L\right)$ & & & & 0.483 \\
\hline$<10$ & $4(23.5)$ & $0(0.0)$ & $4(17.4)$ & \\
\hline $10-100$ & $7(41.2)$ & $2(33.3)$ & $9(39.1)$ & \\
\hline$\geq 100$ & $6(35.3)$ & $4(66.7)$ & $10(43.5)$ & \\
\hline Elevated CSF proteins $(\geq 0.45 \mathrm{~g} / \mathrm{L})$ & $10(58.8)$ & $5(83.3)$ & $15(65.2)$ & 0.369 \\
\hline Intracranial pressure $\left(>250 \mathrm{~mm} \mathrm{H}_{2} \mathrm{O}\right)$ & $14(82.4)$ & $3(50.0)$ & $17(73.9)$ & 0.279 \\
\hline
\end{tabular}

*Underlying diseases included hepatitis B (1 case, 3 controls), renal disease (1 case, 2 controls), diabetes ( 1 case, 1 control), aplastic anemia (1 cases, 1 controls), tuberculosis and hepatitis B (1 case, 1 control), and hand-foot-mouth disease (1 case, 4 controls).

tBirds included pigeons, chicken, or parrots; saprophytes included soils, grassland, or rotten vegetables and fruits. 
Table 2 Univariate conditional logistic analysis of risk factors for cryptococcal meningitis among patients with meningitis and encephalitis

\begin{tabular}{|c|c|c|c|c|}
\hline Factors & $\begin{array}{l}\text { Case } \\
{[\text { no. }(\%)]} \\
(n=13)\end{array}$ & $\begin{array}{l}\text { Control } \\
{[\text { [no.(\%)] }} \\
(n=52)\end{array}$ & $P$ value & OR $(95 \% \mathrm{Cl})$ \\
\hline \multicolumn{5}{|l|}{ Gender } \\
\hline Female & $9(21.4)$ & $51(55.4)$ & \multicolumn{2}{|l|}{ Reference } \\
\hline Male & $14(78.6)$ & $41(44.6)$ & 0.190 & $1.81(0.75-4.38)$ \\
\hline \multicolumn{5}{|l|}{ Age, years } \\
\hline $0-5$ & $4(17.4)$ & $36(39.1)$ & \multicolumn{2}{|l|}{ Reference } \\
\hline $5-10$ & $6(26.1)$ & $29(31.5)$ & 0.612 & $1.51(0.31-7.35)$ \\
\hline $10-15$ & $9(39.1)$ & $21(22.8)$ & 0.033 & $4.36(1.12-9.81)$ \\
\hline $15-17$ & $4(17.4)$ & $6(6.5)$ & 0.029 & $5.53(1.19-25.79)$ \\
\hline \multicolumn{5}{|c|}{ Geographic location } \\
\hline Urban areas & $6(26.1)$ & $32(34.8)$ & \multicolumn{2}{|l|}{ Reference } \\
\hline Rural areas & $17(73.9)$ & $60(65.2)$ & 0.384 & $1.75(0.54-5.66)$ \\
\hline \multicolumn{5}{|c|}{$\begin{array}{l}\text { Time from } \\
\text { illness onset } \\
\text { to hospitalization } \\
\text { (days) }\end{array}$} \\
\hline $1-10$ & $2(8.7)$ & $35(38.0)$ & \multicolumn{2}{|l|}{ Reference } \\
\hline $10-20$ & $3(13.0)$ & $24(26.1)$ & 0.398 & $2.22(0.35-14.15)$ \\
\hline $20-30$ & $12(52.2)$ & $17(18.5)$ & 0.004 & 11.39 (2.20-59.02) \\
\hline$\geq 30$ & $6(26.1)$ & $16(17.4)$ & 0.055 & $5.05(0.96-26.84)$ \\
\hline \multicolumn{5}{|c|}{$\begin{array}{l}\text { Contact with } \\
\text { birds/droppings } \\
\text { or saprophytes* }\end{array}$} \\
\hline No & $5(21.7)$ & $56(60.9)$ & \multicolumn{2}{|l|}{ Reference } \\
\hline Yes & $18(78.3)$ & $36(39.1)$ & 0.001 & $9.32(2.54-34.23)$ \\
\hline \multicolumn{5}{|l|}{$\begin{array}{l}\text { Underlying } \\
\text { disease } †\end{array}$} \\
\hline No & $17(73.9)$ & $80(87.0)$ & \multicolumn{2}{|l|}{ Reference } \\
\hline Yes & $6(26.1)$ & $12(13.0)$ & 0.160 & $2.05(0.75-5.58)$ \\
\hline
\end{tabular}

* Birds included pigeons, chicken, or parrots; saprophytes included soils, grassland, or rotten vegetables and fruits.

† Underlying diseases included hepatitis B (1 case, 3 controls), renal disease ( 1 case, 2 controls), diabetes ( 1 case, 1 control), aplastic anemia ( 1 case, 1 control), tuberculosis and hepatitis $\mathrm{B}(1$ case, 1 control), and hand-foot-mouth disease (1 case, 4 controls).

regional variation in the incidence of $\mathrm{CM}$ among immunocompetent populations.

However, the epidemiologic characteristics, clinical features, and laboratory findings associated with $\mathrm{CM}$ were similar for children with and without underlying diseases. The median age of infected children was about 12 years old, consistent with prior studies of $\mathrm{CM}$ in HIV-negative children [8,9]. Like in other hospital-based reports of CM in children, most of the patients in our study were boys [12,29]. A population-based surveillance in South Africa also showed that boys are significantly more likely to become infected with cryptococcosis than
Table 3 Multivariate conditional logistic analysis of risk factors for cryptococcal meningitis among patients with meningitis and encephalitis

\begin{tabular}{lll}
\hline Risk Factor & $\boldsymbol{P}$ value & OR $\mathbf{( 9 5 \% \mathbf { C l } )}$ \\
\hline $\begin{array}{l}\text { Time from illness onset to hospital } \\
\text { admission ( } \geq 20 \text { day) }\end{array}$ & 0.007 & $5.31(1.58-17.89)$ \\
$\begin{array}{l}\text { Contact with birds/droppings or } \\
\text { saprophytes* }\end{array}$ & 0.004 & $11.82(2.21-62.24)$ \\
\hline
\end{tabular}

* Birds included pigeons, chicken, or parrots; saprophytes included soils, grassland, or rotten vegetables and fruits.

adults, but it did not evaluate the gender distribution for $\mathrm{CM}$ in children [30].

Of the children included in our study, $73.9 \%$ of the patients were from rural areas, suggesting that there is increased environmental exposure in rural areas. Similar results were obtained in a population-based study in Australia and New Zealand [4], although few HIVnegative children with $\mathrm{CM}$ were included in these studies. Furthermore, about half of the $\mathrm{CM}$ cases in our study occurred in summer in Shijiazhuang; the reason for this is unclear. Although time distribution is an important epidemiologic characteristic of diseases, the seasonal distribution of $\mathrm{CM}$ in children has not been reported. When compared to children with meningitis caused by other pathogens, a conditional logistic analysis showed that age, gender, and geographic location were not risk factors for $\mathrm{CM}$ in pediatric patients. We did not test onset of illness as a risk factor, because it was the matching variable in the case-control study. Thus, further studies are needed to confirm whether or not age, gender, geographic location, and onset of illness are risk factors associated with CM in children.

In our study, fever was the most frequent sign of CM, followed by headache, nausea, altered mental status, and vomiting. Hearing and visual damage were less common during the course of the disease. These frequent characteristics were secondary to increased intracranial pressure (ICP) and consistent with the laboratory findings of ICP. Pleocytosis, elevated CSF proteins, and decreased CSF glucose levels were also common. These clinical and laboratory findings are somewhat different from those previously reported in HIV-negative or HIVpositive children $[8,12,29]$. In HIV-negative children with $\mathrm{CM}$, one study reported a meningeal irritation sign to be the most common manifestation, followed by headache, vomiting, and pleocytosis in 9 HIV-negative children with CM [8]. Yet another study described hearing and visual damage to be common symptoms in 11 HIV-negative children with CM [12]. These different clinical and laboratory findings may be due to different patient populations enrolled in the various studies. The main reason for the difference between HIV-negative or HIV-positive children may be the immune status of the 
patients. Overall, the characteristics of CM did not differ from those of other forms of meningitis, thus we could confirm the diagnosis of $\mathrm{CM}$ only through identification of Cryptococcus in the CSF. The difficulty in diagnosis is likely why patients were misdiagnosed with other forms of meningitis prior to CSF culture.

Although the characteristics of $\mathrm{CM}$ are indistinguishable from other forms of meningitis, the treatment may differ. Thus, early identification and prevention are critical for management of $\mathrm{CM}$ in the pediatric population. Infection with HIV/AIDS is the most common risk factor for $\mathrm{CM}$ in adults, followed by other comorbid conditions, such as cancer, organ transplantation, renal disease, and connective tissue disorders. Furthermore, a population-based multistate study revealed smoking and outdoor occupations are associated with an increased risk of cryptococcosis in adults infected with HIV [3]. However, the risk factors associated with $\mathrm{CM}$ in children have not been defined. Our study shows that contact with birds/bird droppings or saprophytes and a longer interval between onset of illness and hospital admission are independent risk factors for $\mathrm{CM}$, but not for other types of meningitis in children. In contrast to children with meningitis due to other pathogens, underlying disease in children with $\mathrm{CM}$ is not a significant risk factor. Thus, our findings suggest that contact with birds/bird droppings or saprophytes and a longer interval between onset of illness and hospital admission may be used to distinguish CM from other types of meningitis in pediatric patients.

Although our observations provide valuable insight into pediatric CM, they are not without limitations. The incidence of HIV-negative children with CM was likely underestimated because only fungal culture was used to identify $C$. neoformans. The traditional diagnostic techniques used to identify this infection include culture analysis, India ink staining of CSF, and cryptococcal polysaccharide antigen detection in the serum and CSF. Lateral flow immunoassay is a new diagnostic method for cryptococcosis, and it shows comparable results to the widely approved enzyme immunoassay for cryptococcal antigen [31]. Although every one of these methods can be used to detect cryptococcosis, a combination of methods may detect more cases with incidences closer to those reported for HIV-negative children with $\mathrm{CM}$ in Shi Jiazhuang. Additionally, the sample size used in this study may have limited the power to detect risk factors although our results are statistically significant and support our conclusion that exposure to birds/bird droppings or saprophytes and the interval from illness onset to hospital admission are independent risk factors for CM. However, a larger sample size may allow detection of additional risk factors. Continuous surveillance or a multicenter study would need to be conducted to detect more cases that could be used to assess for additional risk factors. Furthermore, although half of the $\mathrm{CM}$ cases emerged in summer, this case-control study lacks a matched variable that would have allowed us to determine if there is a seasonal risk of developing pediatric CM.

Overall, our findings suggest that we should reconsider strategies for managing and preventing CM in children. Instead of simply administering drug prophylaxis, a primary, secondary, and tertiary strategy for prevention and control of CM could be tailored to individuals at high risk for CM. For instance, our results suggest that children should avoid contact with birds/bird droppings and saprophytes, sick children should receive medical care as soon as possible, and clinicians need to consider $\mathrm{CM}$ as a potential cause for meningitis especially in boys and in children, who had contact with birds/bird droppings or saprophytes and in children who did not receive prompt medical attention. Furthermore, public health studies are needed to identify and/or develop effective antifungal drugs, vaccines [32], and screening strategies [33].

\section{Conclusions}

In summary, we found that although CM is not common in HIV-negative children, the mortality rate associated with CM is high in HIV-negative children. The epidemiology and clinical and laboratory characteristics of $\mathrm{CM}$ do not differ between HIV-negative children with underlying diseases and those without underlying diseases. Boys and children from rural areas represented most cases of pediatric CM. Children exposed to birds/bird droppings or saprophytes and children who did not receive prompt medical attention were at high risk for $\mathrm{CM}$, whereas these factors were not associated with risk for other types of meningitis. These findings suggest that avoidance of environmental risk factors and prompt medical attention are important for the prevention and management of $\mathrm{CM}$ among children. Clinicians should consider $\mathrm{CM}$ as a potential cause for pediatric meningitis in children with factors mentioned above. Further studies are needed to identify the most effective measures to confront $\mathrm{CM}$.

\section{Abbreviations}

OR: Odds ratio; Cl: Confidence interval.

\section{Competing interests}

The authors declare they have no conflicts of interest.

\section{Authors' contributions}

$J G, J Z, X Z, S Q$, and $Y S$ conceived the study and participated in its design. JG, $J Z, S Z$, and $J$ p participated in coordination and collected data. XZ, SQ, and YS carried out the laboratory tests. JG and SZ analyzed the data. JG and JZ wrote the manuscript. JG and JL audited AMES database regularly. All authors read and approved the final manuscript. 


\section{Acknowledgements}

We thank all clinicians, laboratory technicians, and patients for their support, contributions, and participation. We gratefully acknowledge all of the study staff from Shi Jiazhuang Center for Disease Prevention and Control and Hebei Provincial Center for Disease Prevention and Control for their contributions.

\section{Funding}

This study was supported by the Acute Meningitis-Encephalitis Syndrome (AMES) Surveillance project of the U.S. Centers for Disease Control and Prevention Global Disease Detection and Response Initiative (2007-2008) and by the Actue Meningitis and Encephalitis Surveillance project of China Center for Disease Prevention and Control (2009-2011).

\section{Author details}

'Shi Jiazhuang Center for Disease Prevention and Control (CDC), Shi Jiazhuang 050011, People's Republic of China. ${ }^{2}$ Hebei Provincial children's hospital, Shi Jiazhuang 050019, People's Republic of China. ${ }^{3}$ Hebei Provincial Center for Disease Prevention and Control (CDC), Shi Jiazhuang 050011, People's Republic of China. ${ }^{4}$ Institute for Epidemiology and Health Emergency, Shi Jiazhuang Center for Disease Prevention and Control (CDC), No.3 Li Kang Street, Shi Jiazhuang 050011, China.

Received: 31 October 2012 Accepted: 22 December 2012 Published: 26 December 2012

\section{References}

1. Park BJ, Wannemuehler KA, Marston BJ, Govender N, Pappas PG, Chiller TM: Estimation of the current global burden of cryptococcal meningitis among persons living with HIV/AIDS. AIDS 2009, 23(4):525-530.

2. Mofenson LM, Brady MT, Danner SP, Dominguez KL, Hazra R, Handelsman E, Havens P, Nesheim S, Read JS, Serchuck L, Van Dyke R: Centers for Disease Control and Prevention; National Institutes of Health; HIV Medicine Association of the Infectious Diseases Society of America; Pediatric Infectious Diseases Society; American Academy of Pediatrics. Guidelines for the Prevention and Treatment of Opportunistic Infections among HIV-exposed and HIV-infected children: recommendations from CDC, the National Institutes of Health, the HIV Medicine Association of the Infectious Diseases Society of America, the Pediatric Infectious Diseases Society, and the American Academy of Pediatrics. MMWR Recomm Rep 2009, 58(RR-11):1-166.

3. Hajjeh RA, Conn LA, Stephens DS, Baughman W, Hamill R, Graviss E, Pappas PG, Thomas C, Reingold A, Rothrock G, Hutwagner LC, Schuchat A, Brandt ME, Pinner RW: Cryptococcosis: population-based multistate active surveillance and risk factors in human immunodeficiency virus-infected persons. Cryptococcal Active Surveillance Group. J Infect Dis. 1999, 179(2):449-454.

4. Chen S, Sorrell T, Nimmo G, Speed B, Currie B, Ellis D, Marriott D, Pfeiffer T, Parr D, Byth K: Epidemiology and host- and variety-dependent characteristics of infection due to Cryptococcus neoformans in Australia and New Zealand. Australasian Cryptococcal Study Group. Clin Infect Dis. 2000, 31(2):499-508.

5. Gumbo T, Kadzirange G, Mielke J, Gangaidzo IT, Hakim JG: Cryptococcus neoformans meningoencephalitis in African children with AIDS. Pediatr Infect Dis J 2002, 21(1):54-56.

6. Mirza SA, Phelan M, Rimland D, Graviss E, Hamill R, Brandt ME, Gardner T, Sattah M, de Leon GP, Baughman W, Hajjeh RA: The changing epidemiology of cryptococcosis: an update from population-based active surveillance in 2 large metropolitan areas, 1992-2000. Clin Infect Dis 2003, 36(6):789-794.

7. Othman N, Abdullah NA, Wahab ZA: Cryptococcal meningitis in an immunocompetent child: a case report and literature review. Southeast Asian J Trop Med Public Health 2004, 35(4):930-934

8. Huang KY, Huang YC, Hung IJ, Lin TY: Cryptococcosis in nonhuman immunodeficiency virus-infected children. Pediatr Neurol 2010, 42(4):267-270.

9. Joshi NS, Fisher BT, Prasad PA, Zaoutis TE: Epidemiology of cryptococcal infection in hospitalized children. Pediatr Infect Dis J 2010, 29(12):e91-e95.

10. Ndiaye M, Diagne NR, Seck LB, Sow AD, Sène MS, Diop AG, Sow HD, Ndiaye MM: Cryptococcal meningitis in children: description of 3 cases. Med Trop (Mars). 2011, 71(2):176-178.
11. Chen YY, Lai CH: Nationwide population-based epidemiologic study of cryptococcal meningitis in Taiwan. Neuroepidemiology 2011, 36(2):79-84.

12. Yuanjie Z, Jianghan C, Nan X, Xiaojun W, Hai W, Wanqing L, Julin G: Cryptococcal meningitis in immunocompetent children. Mycoses 2012, 55(2):168-171.

13. $\mathrm{Xu} \mathrm{BP}$, Shen $\mathrm{KL}$, Zhao SY: Disseminated cryptococcosis in 28 previously healthy children. Pediatr Respir Rev. 2012, 13(Supp 1):S83.

14. Mitchell TG, Perfect JR: Cryptococcosis in the era of AIDS-100 years after the discovery of Cryptococcus neoformans. Clin Microbiol Rev 1995, 8(4):515-548.

15. Chayakulkeeree M, Perfect JR: Cryptococcosis. Infect Dis Clin North Am 2006, 20(3):507-544

16. Litvintseva AP, Thakur R, Reller LB, Mitchell TG: Prevalence of clinical isolates of Cryptococcus gattii serotype $\mathrm{C}$ among patients with AIDS in sub-Saharan Africa. Eukaryot Cell 2005, 192(5):888-892.

17. Steele KT, Thakur R, Nthobatsang R, Steenhoff AP, Bisson GP: In-hospital mortality of HIV-infected cryptococcal meningitis patients with C. gattii, C. neoformans infection in Gaborone, Botswana. Med Mycol 2010, 48(8):1112-1115.

18. Chen J, Varma A, Diaz MR, Litvintseva AP, Wollenberg KK, Kwon-Chung KJ: Cryptococcus neoformans strains and infection in apparently immunocompetent patients, China. Emerg Infect Dis 2008, 14(5):755-762.

19. Idnurm A, Bahn YS, Nielsen K, Lin X, Fraser JA, Heitman J: Deciphering the model pathogenic fungus Cryptococcus neoformans. Nat Rev Microbiol 2005, 3(10):753-764.

20. MacDougall L, Kidd SE, Galanis E, Mak S, Leslie MJ, Cieslak PR, Kronstad JW, Morshed MG, Bartlett KH: Spread of Cryptococcus gattii in British Columbia, Canada, and detection in the Pacific Northwest, USA. Emerg Infect Dis 2007, 13(1):42-50.

21. Viviani MA, Cogliati M, Esposto MC, Lemmer K, Tintelnot K, Colom Valiente MF, Swinne D, Velegraki A, Velho R, European Confederation of Medical Mycology (ECMM) Cryptococcosis Working Group: Molecular analysis of 311 Cryptococcus neoformans isolates from a 30-month ECMM survey of cryptococcosis in Europe. FEMS Yeast Res 2006, 6(4):614-619.

22. Okamoto K, Hatakeyama S, Itoyama S, Nukui Y, Yoshino Y, Kitazawa T, Yotsuyanagi H, Ikeda R, Sugita T, Koike K: Cryptococcus gattii genotype VGIla infection in man, Japan, 2007. Emerg Infect Dis 2010, 16(7):1155-1157.

23. Shih CC, Chen YC, Chang SC, Luh KT, Hsieh WC: Cryptococcal meningitis in non-HIV-infected patients. Q J Med 2000, 93(4):245-251.

24. Capoor MR, Nair D, Deb M, Gupta B, Aggarwal P: Clinical and mycological profile of cryptococcosis in a tertiary care hospital. Indian J Med Microbiol 2007, 25(4):401-404.

25. Chau TT, Mai NH, Phu NH, Nghia HD, Chuong LV, Sinh DX, Duong VA, Diep PT, Campbell Jl, Baker S, Hien TT, Lalloo DG, Farrar JJ, Day JN: A prospective descriptive study of cryptococcal meningitis in HIV uninfected patients in Vietnam - high prevalence of Cryptococcus neoformans var grubii in the absence of underlying disease. BMC Infect Dis 2010, 10:199.

26. Pappas PG, Perfect JR, Cloud GA, Larsen RA, Pankey GA, Lancaster DJ, Henderson H, Kauffman CA, Haas DW, Saccente M, Hamill RJ, Holloway MS, Warren RM, Dismukes WE: Cryptococcosis in Human Immunodeficiency Virus-Negative Patients in the Era of Effective Azole Therapy. Clin Infect Dis 2001, 33(5):690-699.

27. Julin $G$, Wang $H$, Liao W, Pan W: Analysis of clinical and immunologic parameters in patients with cryptococcal meningitis[in Chinese]. J Clin Dermatol. 2003, 23(2):72-73.

28. Netea MG, Brouwer AE, Hoogendoorn EH: Two patients with cryptococcal mentingtis and idiopathic CD4 lymphopenia: defective cytokine production and reversal by recombinant interferon-gamma theraphy. Clin Infect Dis 2004, 39(9):e83-e87.

29. Gonzalez CE, Shetty D, Lewis LL, Mueller BU, Pizzo PA, Walsh TJ: Cryptococcosis in human immunodeficiency virus-infected children. Pediatr Infect Dis J 1996, 15:796-800.

30. Meiring ST, Quan VC, Cohen C, Dawood H, Karstaedt AS, McCarthy KM Whitelaw AC, Govender NP, for the Group for Enteric, Respiratory and Meningeal disease Surveillance in South Africa (GERMS-SA): A comparison of paediatric- and adult-onset cryptococcosis detected through population-based surveillance in South Africa, 2005-2007. AIDS 2012, 26. doi:10.1097/QAD.0b013e3283570567.

31. Lindsley MD, Mekha N, Baggett $H C$, Surinthong $Y$, Autthateinchai $R$, Sawatwong P, Harris JR, Park BJ, Chiller T, Balajee SA, Poonwan N: 
Evaluation of a newly developed lateral flow immunoassay for the diagnosis of cryptococcosis. Clin Infect Dis 2011, 53(4):321-5.

32. Denning DW, Hope WW: Therapy for fungal diseases: opportunities and priorities. Trends Microbiol 2010, 18(5):195-204.

33. Roy $M$, Chiller T: Preventing deaths from cryptococcal meningitis: from bench to bedside. Expert Rev Anti Infect Ther 2011, 9(9):715-7.

doi:10.1186/1471-2334-12-376

Cite this article as: Guo et al:: A case-control study of risk factors for HIV-negative children with cryptococcal meningitis in Shi Jiazhuang, China. BMC Infectious Diseases 2012 12:376.

\section{Submit your next manuscript to BioMed Central and take full advantage of:}

- Convenient online submission

- Thorough peer review

- No space constraints or color figure charges

- Immediate publication on acceptance

- Inclusion in PubMed, CAS, Scopus and Google Scholar

- Research which is freely available for redistribution 